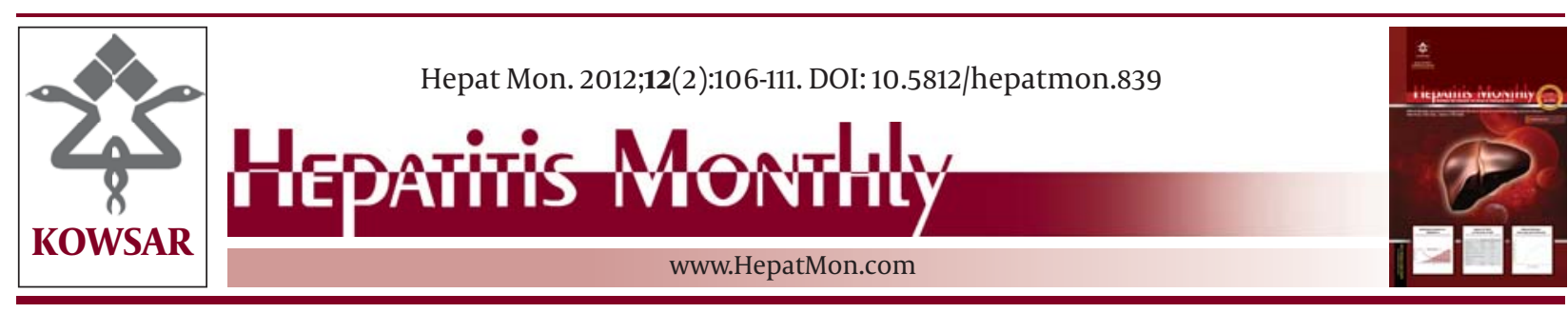

\title{
Impact of Hepatitis C on Survival of HIV-Infected Individuals in Shiraz; South of Iran
}

\author{
Abbas Rezaianzadeh ${ }^{1}$, Jafar Hasanzadeh ${ }^{1}$, Abbas Alipour ${ }^{1 *}$, Mohamed Ali Davarpanah ${ }^{1}$, \\ Abdorreza Rajaeifard ${ }^{1}$, Seyed Hamid Reza Tabatabaee ${ }^{1}$ \\ ${ }^{1}$ Research Center for Health Sciences, Epidemiology Department, School of Health and Nutrition, Shiraz University of Medical Sciences, Shiraz, IR Iran
}

\begin{tabular}{l}
\hline A R T I C L E I N F O \\
\hline Article type: \\
Original Article \\
\hline Article history: \\
Received: 29 Oct 2011 \\
Revised: 04 Feb 2012 \\
Accepted: 14 Feb 2012
\end{tabular}

\section{Keywords:}

HIV

Coinfection

Survival Rate

\begin{abstract}
A B S T R A C T
Background: HIV and HCV infections are basic issues of many health systems. Since HIV and HCV are transmitted similarly, it is common to become infected by them simultaneously. No consensus exists on the effect of HCV infection on the survival of HIV-infected patients.

Objectives: This study aimed to investigate the issue in a relatively large cohort of patients who had a high prevalence of this coinfection in Shiraz (South of Iran).

Patients and Methods: In this historical cohort study, we evaluated the survival time of 1338 HIV-infected individuals who had been referred to a behavioral consultation center in Shiraz over 10 years (from April 2001 to July 2011). Kaplan-Meier method and log-rank test were used to investigate patient survival and compare their survival curves, respectively. Moreover, Cox proportional hazards model was used to examine the effect of HCV infection on patient survival after control for age, sex, having the injection drug use (IDU) risk factor, CD4 count at baseline, more than a 30\% decline in CD4 cell count, and highly active antiretroviral therapy (HAART).

Results: In our cohort, 1044 patients (78.03\%) were infected by HCV. The median follow-up was 43.48 months (95\% CI = 61.18-26.63). The median survival time in HCV-infected and uninfected patients was 163.8 and 194.8 months, respectively $(P=0.039)$. After controlling for other covariates, HCV infection increased the mortality rate 2.13 times more in HCV-infected patients than HCV -uninfected patients (CI: 95\%; 1.1-4.52).

Conclusions: HCV infection increases AIDS-related deaths. To control HCV infection and transmission and eliminate HCV, timely diagnosis and treatment and serious harm reduction programs must be implemented.

Copyright $\odot 2012$ Kowsar M. P. Co. All rights reserved.
\end{abstract}

- Implication for health policy/practice/research/medical education:

There are limited data and study about the impact of HCV on HIV/AIDS related mortality in Iran. Our study enforces on importance of HIV/HCV coinfection for policy makers to persuade this issue in our society.

- Please cite this paper as:

Rezaianzadeh A, Hasanzadeh J, Alipour A, Davarpanah MA, Rajaeifard A, Tabatabaee SHR. Impact of Hepatitis C on Survival of HIVInfected Individuals in Shiraz; South of Iran. Hepat Mon. 2012;12(2):106-11. DOI:10.5812/hepatmon.839

\section{Background}

HIV and HCV infections are basic issues that are faced by health systems in many societies. Because HIV and HCV are transmitted in similar ways, it is common to be-

* Corresponding author: Abbas Alipour, Epidemiology Department, School of Health and Nutrition, Shiraz University of Medical Sciences, Shiraz, IR Iran, Tel: +98-7117251001, Fax: +98-7117260225, E-mail: alipour_abbass@yahoo.com

DOI:10.5812/hepatmon.839

Copyright $\odot 2012$ Kowsar M.P.Co. All rights reserved. come coinfected by them (1-3). It is estimated that 34-38.6 million people around the world are infected by HIV compared with 170-200 million by HCV and 4-5 million people who are coinfected with $\operatorname{HIV}$ and $\operatorname{HCV}(4,5)$. It is also estimated that $68,000-110,000$ people $(6)($ average $=$ 86,000 , less than $0.2 \%$ ) in Iran are infected by HIV (7), and less than $1 \%$ is infected by HCV (8). The prevalence of HIV and HCV coinfection depends on facilitating risk factors, such as IDU, and varies between countries-even between various areas within a country (9-12). Surveys show that 
the prevalence of this coinfection in HIV-infected individuals who have a background of IDU is $92 \%, 91 \%$, and over 90\% in the US (13), Russia (14), and Asia (12), respectively. Although many studies have shown that HIV infection leads to a decrease in HCV clearance and increases in viral load and complications from the infection (15-17), no consensus exists regarding the effect of HCV infection on the natural process of HIV infection. Some studies have revealed that this coinfection affects HIV progression and its related mortality $(18,19)$. Other studies, however, have not shown the same results-especially after the wide use of HAART $(20,21)$. In other words, considering HAART and controlling its effects, no consensus exists regarding the effect of HIV infection on general survival or HIV-related survival in HIV patients (22). In addition, few studies have been conducted on the survival of HIV patients and its factors in Iran.

\section{Objectives}

This study aimed to investigate the effect of HCV infection-after controlling for the effects of HAART-on survival in a relatively large cohort of HIV patients who have a high prevalence of HCV coinfection in Shiraz (South of Iran).

\section{Patients and Methods}

The registration of HIV patients who participated in this cohort study began in April 2001. These patients were diagnosed as definite HIV infections (by serial ELISA and western blot) among thousands of individuals referred to this center due to risky behaviors. In the center, HIV-infected patients receive free services, such as regular laboratory and radiological exams, medications prescribed by a physician, and personal and familial consultations. The interviewers were well trained and familiar with the patients under study. Also, the quality control of the data was done by a researcher. Through July 15, 2011, 1683 HIV patients took part in this study. The participation criteria included being visited twice by an infectious disease specialist in the past 18 months, determination of their survival status in the past 6 months, age over 17 years, and to be in the cohort study at least for 12 months. Accordingly, 1338 patients met the criteria. HAART treatment was performed for some patients in this center in 2003. Since 2004, however, it has been done routinely for eligible patients, based on WHO instructions and their adjusted forms, which were prepared and supplied by the Iranian Ministry of Health and Medical Education (this treatment does not differ between HIV infected and HIV/HCV coinfected subjects). The causes of participants' deaths were gathered from their profiles and confirmed by the general practitioner of the center, who was familiar with the patients. In cases for which the status of death was not known, the center's social work department called the intended patients or their families and confirmed the patient's survival status. If a patient was dead, the exact cause of death was determined and re- corded through hospital profiles or the death certificate. Then, the causes of definite HIV- and AIDS-related deaths were identified and examined as the event of the study (23). A venous sample was taken by a professional phlebotomist from the arms of all subjects who participated in the blood test. By ELIZA, the samples were screened for anti-HIV (Delaware Biotech Inc., USA), and the diagnosis of HIV was confirmed by western blot (Diagnostic, Germany). A third-generation ELISA (Dia. Pro, Italy) was used to determine anti-HCV. Positive results from both the western blot (for HIV) and third-generation ELISA (for HCV) were considered coinfection with HIV and HCV. CD4+ cell counts were measured by flow cytometry (Partec, Germany). The project was approved by the vice chancellor for research affairs, Shiraz University of Medical Sciences.

Two periods were defined for the patients: before HAART (before 2004) for patients who had been registered before 2004 and during HAART for patients who had been registered after 2004 . The patients were categorized into 2 groups: those who were infected with HCV and those who were not. The characteristics of the study participants were compared by chi-square test and t-test regarding the qualitative and quantitative variables, respectively. The mortality rate from AIDS-related complications was calculated by dividing the number of deaths by time-persons of follow-up in the subgroups; $95 \%$ confidence intervals were also calculated. Survival curves of the 2 groups were drawn and compared by Kaplan-Meier method and log-rank test. Moreover, Cox proportional hazards model was used to examine the effect of HCV infection on patient survival, controlling for age, sex, IDU, CD4 count at baseline, a greater than 30\% decline in CD4 cell count during the study, and HAART treatment. The assumption of analysis in the Cox model was evaluated using parallel survival curves. In the survival analyses, the time of patient registration and entrance into the cohort was considered the starting point (T0), and AIDSrelated death was considered the event of the study. Statistical analyses were performed using SPSS (version 16) and Stata (version 10).

\section{Results}

In this study, 1338 HIV patients-204 (15.2\%) of whom were women-were investigated. The median age was 36 (32-42) years; 1044 (78.03\%) of these patients were infected by HCV. The median follow-up was 43.48 (61.18-26.63) months. Other characteristics of the population, based on HCV status, are shown in Table 1. Most of the HCVinfected individuals were males and older and had risk factors of more IDU and longer follow-ups in the study. The rate of AIDS-related deaths decreased to $74.8 \%$ after 2004 and from 5.59 (95\%CI: 3.93-7.96) to 1.41 (95\% CI: 1.11.82) deaths per 100 person-years $(P<0.0001)$. The rate of AIDS-related deaths increases $23.23 \%$ in people with HIV/ HCV coinfection compared with patients with HIV. The mortality rate in patients with HIV/HCV coinfection has been 1.98 (95\% CI: 1.59 - 2.48) deaths in 100 person-year, 
Table 1. Demographic and Baseline Characteristics of the Study Cohort Divided Into the Groups Infected With Hepatitis C Virus and Not Infected With Hepatitis Virus C

\begin{tabular}{|c|c|c|c|c|}
\hline & Patients, $(\mathrm{n}=1338)$ & HCV Group, $(\mathrm{n}=1044)$ & Non-HCV Group, $(n=294)$ & $P$ value \\
\hline Females, No. (\%) & $204(15.2)$ & $36(3.4)$ & $168(57.1)$ & $<0.0001$ \\
\hline Age, median (range) & $36(32-42)$ & $37(32-43)$ & $35(31-42)$ & 0.002 \\
\hline IDU risk factor, No. (\%) & $987(73.8)$ & $918(87.9)$ & $69(23.5)$ & $<0.0001$ \\
\hline $\begin{array}{l}\text { Fallow up time in month, median } \\
\text { (range) }\end{array}$ & $43.48(26.23-61.58)$ & $45.33(27.74-62.5)$ & $37.3(20.6-54.8)$ & 0.006 \\
\hline $\begin{array}{l}\text { CD } 4 \text { cell count at base line } \leq 200 \text { cells } / \\
\mu \mathrm{L}, \text { No. }(\%)\end{array}$ & $306(22.9)$ & $224(21.5)$ & $82(27.9)$ & 0.78 \\
\hline $\begin{array}{l}>30 \% \text { decline in CD } 4 \text { cell count at fallow } \\
\text { up time, No. (\%) }\end{array}$ & $145(10.8)$ & $106(10.2)$ & $39(13.3)$ & 0.89 \\
\hline HAART therapy, No. (\%) & & & & 0.75 \\
\hline No (before 2005) & $134(10)$ & $106(10.2)$ & $28(9.5)$ & \\
\hline Yes (after 2005) & $1204(90)$ & $938(89.8)$ & $266(90.5)$ & \\
\hline
\end{tabular}

\begin{tabular}{|c|c|c|c|c|}
\hline & Value or Characteristic Compared & Crude Hazards Ratio & Adjusted Hazards Ratio & $P$ value \\
\hline Age & 1 year increasing & $0.997(0.975-1.02)$ & $0.99(0.96-1.02)$ & 0.647 \\
\hline Sex & Female $v s$. male & $0.57(0.28-1.17)$ & $0.54(0.2-1.44)$ & 0.216 \\
\hline IDU & Non IDU vs. IDU & $0.996(0.63-1.57)$ & $0.84(0.46-1.54)$ & 0.57 \\
\hline CD4 cell count at base line & $<200 v s . \geq 200$ cells $/ \mu \mathrm{L}$ & $4.3(2.5-7.2)$ & $5.38(3.04-9.51)$ & $<0.0001$ \\
\hline $\begin{array}{l}\text { Decline in CD4 cell count } \\
\text { during fallow up }\end{array}$ & Yes vs. No & $1.64(0.95-2.8)$ & $2.93(1.65-5.2)$ & $<0.0001$ \\
\hline $\mathrm{HCV}$ & Positive $v s$. Negative & $1.9(1.1-3.5)$ & $2.13(1.1-4.52)$ & 0.048 \\
\hline HAART & Yes vs. No & $0.36(0.21-0.59)$ & $0.46(0.24-0.86)$ & 0.015 \\
\hline
\end{tabular}

while it has been reported as 1.52 (95\% CI: 0.92 - 2.52) deaths in 100 person-year in only HIV infected patients. $(P=0.03)$. These rates in HIV/HCV-coinfected persons in the pre-HAART and post-HAART periods were 5.51 (95\% CI: 3.62-8.37) and 1.58 (95\% CI: 1.21-2.06) per 100 personyears, respectively $(P<0.0001)$. Also, the mortality rate was compared between the patients with baseline CD4 counts below and above 200 , which showed an $82.33 \%$ increase in patients with baseline CD4 counts below 200. The mortality rate of the first group (patients with baseline CD4 counts below 200) was 4.3 (95\% CI:3.25-5.69) per 100 person-years versus 0.76 (95\% CI: 0.47-1.25) per 100 person-years in the second group (patients with baseline CD4 above 200 $)(P<0.0001)$. The median survival time in the HCV-infected and uninfected patients was 163.8 and 194.8 months, respectively $(P=0.039)$. In the multivariate analysis (Table 2), it was revealed that after controlling for covariates, HCV infection increased the number of deaths in HCV-infected patients 2.13 times (95\% CI:1.1-4.52) more than HCV-uninfected patients. Covariates of HAART (aHR $=0.46$; 95\% CI: 0.24-0.86), CD4 count at baseline (aHR = 5.38; 95\% CI: 3.04-9.51), and more than a 30\% decline in CD4 count $(\mathrm{aHR}=2.93 ; 95 \% \mathrm{CI}: 1.65-5.2)$ correlated with survival length in the follow-up $(P<0.05)$. In order to estimate rates of survival by HCV status according to IDU and sex, 2 Cox analyses were performed with the (HCV $\times$ IDU and $\mathrm{HCV} \times$ sex) interaction terms in the models. The lack of statistical significance between these interactions ( $P=0.987$ and $P=0.858$, respectively) showed that the effect of HCV on HIV survival was not modified by IDU or gender and did not require a separate analysis.

\section{Discussion}

In our large cohort study, the prevalence of HIV/HVC coinfection was $78 \%$. This coinfection was related to IDU background. Intravenous drug use has been the predominant mode of transmission of HCV in the world (24, 25 ), and approximately 75\% HIV-positive people in Iran are IDUs (26). The results of the present study are consistent with previous national $(27,28)$ as well as international $(29,30)$ studies and emphasize IDU as one of the major routes of HVC transmission. Our study revealed that HAART treatment leads to a 54\% decrease in AIDS-related deaths. Other studies have also shown that HAART treatment results in a decrease in mortality rate in HIV patients 3 to 10 times more than untreated HIV patients with HAART and changes HIV/AIDS into a chronic disease (31). The international experience has shown that before commencement of HAART treatment, almost all HIV patients died due to AIDS-related diseases; today, however, almost half of these patients in North America and Europe die from reasons that are not related to AIDS (32). HAART treatment not only decreases necrotic inflamma- 
tion and progressive liver diseases $(33,34)$ but also reduces the replication of viruses in the liver (34) and increases the CD4 count (35). On the other hand, HAART treatment is advised to be performed before beginning HCV treatment, since it may cause fibrosis through cumulative hepatotoxicity in HIV/HCV-coinfected patients.

Regardless, the results of the present study were consistent with the results of other studies, and emphasize the important role of HAART treatment in the survival of HIV patients (36). As expected, CD4 count at baseline correlated with AIDS-related death. CD4 T cells are the primary target of HIV and an important marker in evaluating the immune system's health. Decline of CD4 cells through increased infections by opportunistic diseases results in an rise in HIV-related deaths (32). In addition to CD4 count at baseline and last CD4 count before HAART treatment, the duration of a patient's life with a high CD4 count influences his prognosis; a 30\% decline in CD4 count during the follow-up shows that patients are more at risk and consequently affects their survival $(31,37)$. These results are consistent with the results of other researchers and emphasize the importance of the follow-up of patients' CD4 count during HAART (38). The results of the present study show that HCV infection in HIV-infected patients increases AIDS-related deaths by 2.13 times, consistent with most of the results of other studies $(18,39,40)$. On the other hand, many studies have not found a relationship between this coinfection and overall death rates before HAART treatment or between this coinfection and AIDS-related deaths after HAART treatment, as shown in a meta-analysis of 30 studies and over 100,000 patients (22). These variations might be due to the type of HAART treatment, adherence of patients to HAART treatment, different endpoints, various sample sizes, different follow-up times, and ignoring some altering factors. Fortunately, the type of treatment and the definition of AIDS-related death are clear in our population; ie, per the Shiraz Center of Behavioral Consult. The sample size and the follow-up time are also suitable. Although no independent studies have been conducted on the status of patient adherence in this center, primary surveys as well as the experiences of doctors report the $25 \%$ to $30 \%$ treatment failure, which is in line with other national studies (41). The treatment failure might be affected by the high proportion of IDU and, consequently, the high proportion of HIV/HCV coinfection, which strongly affects patient adherence to HAART treatment. In spite of the fact that the mechanisms through which HCV infection worsens the condition of HIV patients and increases its complications and AIDS-related deaths are not clear, it likely activates immune cells with the CD4 apoptosis marker and causes a severe defect in the immune system (42), decreasing the power of recovery in CD4 T cells after HAART treatment (43); increasing the production of cryoglobulin by activation of B cells (44), decreasing the production of CRP (45); and activating the replication of HCV in lymphoid (46) and lymphoblastic (47) tissues as well as in environmental CD4 T cells in
HIV patients (48). The present study revealed that HAART treatment is highly effective in HIV patients in Iran. In addition, HCV coinfection, as an independent factor, can threaten these patients. These findings should prompt us to prevent $\mathrm{HCV}$ infection and eliminate this virus in HIV patients. Conducting programs for screening blood of HCV and HCV RNA antibodies is quite beneficial. Fortunately, this program is being seriously conducted in Iran and, particularly, Fars (49), as well as some developed and developing countries. Harm reduction programs in at-risk populations - particularly HIV patients - is also of great importance. Fortunately, these programs are also being conducted in a high quantity and quality in Iran; in 2007, the Iranian health system distributed 1,400,000 syringes in DIC and outreach teams that provide harm reduction services over 6 months (50). Therefore, this coinfection should decrease. Nevertheless, based on other countries' previous experiences, harm reduction programs for HCV transmission in IDU people are less effective than for those with HIV. This is probably due the higher transmission of HCV and the larger number of HCV-infected patients in the IDU population (12). Timely diagnosis of HCV infection is also of great significance (12). In the next stage, the effective treatment of these patients, as secondary prevention, is quite influential; however, it was not widely performed in the population under our investigation.

Surveys show that less than $10 \%$ of the 170 million HCVinfected patients around the world are aware of their disease. As man is the only reservoir of HCV, elimination of the virus is not that far-fetched. Moreover, in contrast to HBV and HIV, there is no latent reservoir for this virus; and when a patient is cured, the danger of transmission of the virus to others is eliminated. If the environmental reservoir is sufficiently decreased, the infection cannot be transmitted easily, allowing the virus transmission cycle to be broken easily using proper disinfectants (12). The present study had some limitations. Since HCV RNA could not be detected routinely in the population under study, HCV infection could only be diagnosed by serology, based on HCV Ab. Of course, this could not strongly affect the results of our study, since at least 1 year had passed from the participants' HIV infection and their entrance into the cohort. Further, the sensitivity of HCV $\mathrm{Ab}$ is over 99\% (51). On the other hand, as others have mentioned, serological study of HCV infections might underestimate the effect of HCV on AIDS-related complications. Therefore, had we measured HCV RNA, we would have observed a stronger relationship between HCV infection and AIDS-related deaths (51). The second limitation was that the role of some infections, such as GB virus C and transfusion transmitted virus (TT Virus), was not investigated with regard to the relationship between HCV infection and AIDS-related deaths, since they were not routinely measure in our study population. As others have also shown, GB virus $C$ leads to a decrease in HIV replication and improvements in HIV patients' survival. On the other hand, it can be sexually transmitted, 
and its prevalence is the same in infected people, IDU people, and other groups. Therefore, this virus cannot have altered the relationship between HCV infection and AIDS-related deaths (19).

Third, we did not know the exact time of HIV and HCV infection; thus, we considered the time of the laboratory exam as the time of infection. However, this moot point can change the actual impact of HCV on HIV/AIDS-related endpoints. Although our study revealed that HCV infection was diagnosed after HIV infection and entrance of the subjects into the study in nearly $90 \%$ of subjects, the exact time of HCV infection is not known. Fourth, because subjects entered our study at different stages of HIV/AIDS, it was very difficult to control for disease state on survival estimations. Fortunately, our evaluation revealed that because the center is unique in Shiraz, nearly all of our subjects were in the initial stages of infection. Besides, the impact of disease progression on survival was controlled by the baseline and trend of CD4 counts. The study sample was selected from a large population of HIV patients who solely and inevitably demand the country's health and treatment centers to treat their disease. These patients are from different cultural, social, and economic backgrounds. Further, because this center is the only provider of such services in Fars and some parts of southern Iran, this sample is a proper representative of the population of HIV patients in southern Iran. Moreover, regarding the results of other studies and considering the similarities between our study population and other parts of Iran, this sample can also be a proper representative of the entire country (52). HAART treatment in the Iranian study population obviously improved HIV patients' survival. After controlling for the effect of HAART treatment, HCV infection resulted in an increase in AIDS-related deaths. In addition, our study enjoys a major practical application: it emphasizes the necessity of timely diagnosis and treatment, as well as serious harm reduction programs, in order to control and eliminate HCV infection and transmission.

\section{Acknowledgements}

This study was financially supported by vice chancellor for research affairs, Shiraz University of Medical Sciences; through contract no 90-5605 (part of Ph.D thesis of Dr Abbas Alipour). Authors would like to acknowledge cooperation of head of HIV research center, Dr. Hasan Julaee and his colleagues, head of local center for disease prevention and control (CDC), Dr. Parvin Afsar Kazerooni and her colleague Dr. sabet, and colleagues in Shiraz Center of Behavioural Consult and Health Presentation, Ms. Mahnaze Nowzarian, Mr. Mohammad Ali Musavi, Mr. Ansari, Mr. Mahdi Shirazi, Mr. Esmaeel Rezaee and Mr. Behzad Rezaee in this study.

\section{Authors' Contribution}

All the authors contributed to all parts of research, contribution is based on approximate time contributed by all. Abbas Rezaianzadeh (20\%), Jafar Hasanzadeh (20\%), Abbas Alipour (30\%), Mohamed Ali Davarpanah (10\%), Abdorreza Rajaeifard (10\%), Seyed Hamid Reza Tabatabaee $(10 \%)$

\section{Financial Disclosure}

None declared.

\section{Funding/Support}

None declared.

\section{References}

1. Leeratanapetch N, Suseangrut W. Hepatitis B Virus and Hepatitis C Virus Co-Infection with HIV Patients at Khon Kaen Hospital. Khon Kaen Hosp Med J. 2008;32(2):229-38.

2. Modi A, Feld J. Viral hepatitis and HIV in Africa. AIDS Rev. 2007;9:25-39.

3. Forbi J, Gabadi S, Alabi R, Iperepolu H, Pam C, Entonu P, et al. The role of triple infection with hepatitis B virus, hepatitis $C$ virus, and human immunodeficiency virus (HIV) type-1 on CD4+ lymphocyte levels in the highly HIV infected population of NorthCentral Nigeria. Mem Inst Oswaldo Cruz, Rio de Janeiro. 2007;102:13.

4. Koziel MJ, Peters MG. Viral Hepatitis in HIV Infection. $N$ Engl J Med. 2007;356:1445-54.

5. van de L, Thijs J, Matthews G, Prins M, Danta M. Acute hepatitis C in HIV-infected men who have sex with men: an emerging sexually transmitted infection. AIDS. 2010;24(12):1799-812.

6. Report on the Global AIDS Epidemic. 2008; Available From: http://www.unaids.org/en/dataanalysis/epidemiology/2008rep ortontheglobalaidsepidemic/.

7. Country Report on Monitoring of the United Nations General Assembly Special Session on HIV and AIDS. National AIDS Committee Secretariat. Tehran, Ministry of Health and Medical Education; 2010 Feb.

8. Alavian S, Adibi P, Zali M. Hepatitis C virus in Iran: epidemiology of an emerging infection. Arc Iranian Medicine. 2005;8:84-90.

9. Alter M, . Epidemiology of viral hepatitis and HIV co-infection. J Hepatol. 2006;44:6-9.

10. Jindal N, Arora U, Singh K. Prevalence of human immunodeficiency virus (HIV), hepatitis B virus, and hepatitis C virus in three groups of populations at high risk of HIV infection in Amritsar (Punjab), Northern India. Jpn J Infect Dis. 2008;61(1):79-81.

11. Rockstroh J. Management of hepatitis B and C in HIV coinfected patients. J Acquir Immune Defi c Syndr. 2003;34:59-65.

12. Thomas DL, Leoutsakas D, Zabransky T, Kumar MS. Hepatitis C in HIV-infected individuals: cure and control, right now. J Int AIDS Soc. 2011;14:22.

13. Rockstroh JK, Mocroft A, Soriano V, Tural C, Losso MH, Horban A, et al. Influence of hepatitis $C$ virus infection on HIV-1 disease progression and response to highly active antiretroviral therapy. $J$ Infect Dis. 2005;192(6):992-1002.

14. Abdala N, Carney JM, Durante AJ, Klimov N, Ostrovski D, Somlai AM, et al. Estimating the prevalence of syringe-borne and sexually transmitted diseases among injection drug users in St Petersburg, Russia. Int J STD AIDS. 2003;14(10):697-703.

15. Gilleece YC, Browne RE, Asboe D, Atkins M, Mandalia S, Bower $\mathrm{M}$, et al. Transmission of hepatitis $\mathrm{C}$ virus among HIV-positive homosexual men and response to a 24-week course of pegylated interferon and ribavirin. J Acquir Immune Defic Syndr. 2005;40(1):41-6.

16. Danta M, Semmo N, Fabris P, Brown D, Pybus O, Sabin C, et al. Impact of HIV on host-virus interactions during early hepatitis C virus infection. J Infect Dis. 2008;197:1588-66.

17. Schnuriger A, Dominguez S, Guiguet M, Harfouch S, Samri A, Ouazene Z, et al. Acute hepatitis C in HIV-infected patients: rare spontaneous clearance correlates with weak memory CD4 T-cell responses to hepatitis C virus. AIDS. 2009;23:2079-89.

18. Greub G, Ledergerber B, Battegay M, Grob P, Perrin L, Furrer $\mathrm{H}$, et al. Clinical progression, survival, and immune recovery 
during antiretroviral therapy in patients with HIV-1 and hepatitis C virus coinfection: the Swiss HIV Cohort Study. Lancet. 2000;356(9244):1800-5.

19. De Luca A, Bugarini R, Lepri AC, Puoti M, Girardi E, Antinori A, et al. Coinfection with hepatitis viruses and outcome of initial antiretroviral regimens in previously naive HIV-infected subjects. Arch Intern Med. 2002;162(18):2125-32.

20. Riley ED, Bangsberg DR, Guzman D, Perry S, Moss AR. Antiretroviral therapy, hepatitis $C$ virus, and AIDS mortality among San Francisco's homeless and marginally housed. J Acquir Immune Defic Syndr. 2005;38(2):191-5.

21. Hung CC, Chen MY, Hsieh SM, Hsiao CF, Sheng WH, Chang SC. Impact of chronic hepatitis $\mathrm{C}$ infection on outcomes of patients with an advanced stage of HIV-1 infection in an area of low prevalence of co-infection. Int J STD AIDS. 2005;16(1):42-8.

22. Chen TY, Ding EL, Seage Iii GR, Kim AY. Meta-analysis: increased mortality associated with hepatitis C in HIV-infected persons is unrelated to HIV disease progression. Clin Infect Dis. 2009;49(10):1605-15.

23. Taffa N, Will JC, Bodika S, Packel L, Motlapele D, Stein E, et al. Validation of AIDS-related mortality in Botswana. J Int AIDS Soc. 2009;12:24.

24. Mauss S, Berg T, Rockstroh J, Sarrazin C, Wedemeyer H. Hepatology. A Clinical Textbook. 2 ed. Düsseldorf: Flying Publisher; 2010.

25. Bostan N, Mahmood T. An overview about hepatitis C: A devasting virus. Crit Rev Microbiol. 2010;36(2):91-133.

26. Rahimi-Movaghar A, Amin-Esmaeili M, Haghdoost AA, Sadeghirad $\mathrm{B}$, Mohraz M. HIV prevalence amongst injecting drug users in Iran: A systematic review of studies conducted during the decade 1998-2007. Int J Drug Policy. 2011:[Epub ahead of print].

27. SeyedAlinaghi S, Jam S, Mehrkhani F, Fattahi F, Sabzvari D, Kourorian Z, et al. Hepatitis-C and Hepatitis-B Co-Infections in Patients with Human Immunodeficiency Virus in Tehran, Iran. Acta Med Iran. 2011;49(4):252-57.

28. Azarkar Z, Sharifzadeh G. Evaluation of the Prevalence of Hepatitis B, Hepatitis C, and HIV in Inmates with Drug-Related Convictions in Birjand, Iran in 2008. Hepat Mon. 2010;10(1):26-30.

29. Buxton J, Amanda Y, Kim P, Spinelli J, Kuo M, Alvarez M, et al. Hcv co-infection in HIV positive population in British Columbia, Canada. BMC Public Health. 2010;10:225.

30. Amin J, Kaye M, Skidmore S, Pillay D, Cooper D, Dore GJ. HIV and hepatitis C co-infection within the CAESAR study. HIV Med. 2004;5:174-9.

31. Torti C, Lapadula G, Maggiolo F, Casari S, Suter F, Minoli L, et al. Predictors of AIDS-defining events among advanced naive patients after HAART. HIV Clin Trials. 2007;8(3):112-20.

32. Taege A. Seek and treat: HIV update 2011. Cleve Clin J Med. 2011;78(2):95-100.

33. Sulkowski MS. Management of hepatic complications in HIVinfected persons. J Infect Dis. 2008;197 (Suppl 3):S279-93.

34. Pascual-Pareja JF, Caminoa A, Larrauri C, Gonzalez-Garcia J, Montes ML, Diez J, et al. HAART is associated with lower hepatic necroinflammatory activity in HIV-hepatitis C virus-coinfected patients with CD4 cell count of more than 350 cells/microl at the time of liver biopsy. AIDS. 2009;23(8):971-5.

35. Thompson MA, Aberg JA, Cahn P, Montaner JS, Rizzardini G, Telenti A, et al. Antiretroviral treatment of adult HIV infection: 2010 recommendations of the International AIDS Society-USA panel. JAMA. 2010;304(3):321-33.

36. Quinn TC. HIV epidemiology and the effects of antiviral therapy on long-term consequences. AIDS. 2008;22(Suppl 3):S7-12.

37. Macias J, Pineda JA, Lozano F, Corzo JE, Ramos A, Leon E, et al. Impaired recovery of $\mathrm{CD} 4+$ cell counts following highly active antiretroviral therapy in drug-naive patients coinfected with human immunodeficiency virus and hepatitis $\mathrm{C}$ virus. Eur J Clin
Microbiol Infect Dis. 2003;22(11):675-80.

38. Bonacini M, Louie S, Bzowej N, Wohl AR. Survival in patients with HIV infection and viral hepatitis B or C: a cohort study. AIDS. 2004;18(15):2039-45.

39. Stebbing J, Waters L, Mandalia S, Bower M, Nelson M, Gazzard B. Hepatitis $C$ virus infection in HIV type 1-infected individuals does not accelerate a decrease in the CD4+ cell count but does increase the likelihood of AIDS-defining events. Clin Infect Dis. 2005;41(6):906-11.

40. Voirin N, Trepo C, Miailhes P, Touraine JL, Chidiac C, Peyramond $\mathrm{D}$, et al. Survival in HIV-infected patients is associated with hepatitis $\mathrm{C}$ virus infection and injecting drug use since the use of highly active antiretroviral therapy in the Lyon observational database. JViral Hepat. 2004;11(6):559-62.

41. Rasoolinejad M, Hajabdolbaghi M, Mohraz M, Zarinfar N, Mohajerani SA. Clinical Outcomeof Hiv Infected Patients According To Immunologic Response After Highly Active Antiretroviral Therapy. Acta Med Iran. 2005;43(1):25-31.

42. Kovacs A, Karim R, Mack WJ, Xu J, Chen Z, Operskalski E, et al. Activation of CD8 T cells predicts progression of HIV infection in women coinfected with hepatitis C virus. J Infect Dis. 2010;201(6):823-34.

43. Potter M, Odueyungbo A, Yang H, Saeed S, Klein MB. Impact of hepatitis $\mathrm{C}$ viral replication on $\mathrm{CD} 4+\mathrm{T}$-lymphocyte progression in HIV-HCV coinfection before and after antiretroviral therapy. AIDS. 2010;24(12):1857-65.

44. Lapinski TW, Parfieniuk A, Rogalska-Plonska M, Czajkowska J, Flisiak R. Prevalence of cryoglobulinaemia in hepatitis C virus- and hepatitis $C$ virus/human immunodeficiency virusinfected individuals: implications for renal function. Liver Int. 2009;29(8):1158-61.

45. Reingold J, Wanke C, Kotler D, Lewis C, Tracy R, Heymsfield S, et al. Association of HIV infection and HIV/HCV coinfection with C-reactive protein levels: the fat redistribution and metabolic change in HIV infection (FRAM) study. J Acquir Immune Defic Syndr. 2008;48(2):142-8.

46. Gonzalez VD, Falconer K, Blom KG, Reichard O, Morn B, Laursen AL, et al. High levels of chronic immune activation in the T-cell compartments of patients coinfected with hepatitis $\mathrm{C}$ virus and human immunodeficiency virus type 1 and on highly active antiretroviral therapy are reverted by alpha interferon and ribavirin treatment. J Virol. 2009;83(21):11407-11.

47. Peters L, Mocroft A, Soriano V, Rockstroh JK, Losso M, Valerio L, et al. Hepatitis $\mathrm{C}$ virus coinfection does not influence the CD4 cell recovery in HIV-1-infected patients with maximum virologic suppression. J Acquir Immune Defic Syndr. 2009;50(5):457-63.

48. Korner C, Kramer B, Schulte D, Coenen M, Mauss S, Fatkenheuer $\mathrm{G}$, et al. Effects of HCV co-infection on apoptosis of CD4+ T-cells in HIV-positive patients. Clin Sci (Lond). 2009;116(12):861-70.

49. Kasraian L, Tavasoli A. Positivity of HIV, hepatitis B and hepatitis $C$ in patients enrolled in a confidential self-exclusion system of blood donation: a cross-sectional analytical study. Sao Paulo Med J. 2010;128(6):320-3.

50. Rahimi-Movaghar A, Razaghi E, Sahimi-Izadian E, Amin-Esmaeili M. HIV, hepatitis C virus, and hepatitis B virus co-infections among injecting drug users in Tehran, Iran. Int J Infect Dis. 2010;14:28-33.

51. Sulkowski MS, Moore RD, Mehta SH, Chaisson RE, Thomas DL. Hepatitis C and progression of HIV disease. JAMA. 2002;288(2):199-206.

52. Hosseini M, SeyedAlinaghi S, Kheirandish P, Esmaeli Javid G, Shirzad H, Karami N, et al. Prevalence and correlates of co-infection with human immunodeficiency virus and hepatitis $C$ virus in male injection drug users in Iran. Arch Iran Med. 2010;13(4):31823. 